\title{
COMPARISON OF NEONATAL APGAR SCORES AND PATIENT SATISFACTION LEVELS IN SPINAL VERSUS GENERAL ANESTHESIA IN ELECTIVE CESAREAN SECTIONS
}

\author{
Syed Khurram Naseer, Aijaz Ali*, Shizan Hamid Feroz, Danish, Amir Sohail \\ Combined Military Hospital Peshawar/National University of Medical Sciences (NUMS) Pakistan, ${ }^{*}$ Combined Military Hospital Badin/National University of \\ Medical Sciences (NUMS) Pakistan
}

\section{ABSTRACT}

Objective: To compare patients undergoing cesarean section under spinal and general anesthesia in terms of neonatal APGAR scores and patient satisfaction.

Study Design: Comparative cross-sectional study.

Place and Duration of Study: Departments of Anesthesia and Gynecology and Obstetrics, Combined Military Hospital Peshawar, for six months from Mar to Aug 2019.

Methodology: In this study, 120 females with a singleton pregnancy of 36-40 weeks, and requiring a non-emergency elective cesarean section were enrolled through consecutive sampling in the study. The patients were randomly allocated into two equal groups of 60 women each through random table numbers. Group A received spinal anesthesia and group B general anesthesia. APGAR score was assessed at 5 minutes after delivery, and score of $\geq 7$ was taken as satisfactory. Patient's satisfaction level regarding anesthesia was recorded on a visual analogue scale of 0 (extremely unsatisfied) to 10 (completely satisfied), and score of $\geq 7$ was taken as satisfactory.

Results: Women receiving general anesthesia were more satisfied as compared to receiving spinal anesthesia (95\% vs. $78.3 \%$; $p$-value 0.007). There was no significant difference in terms of APGAR scores in general anesthesia and spinal anesthesia (83.33\% versus $90 \%$; $p$-value 0.283$)$.

Conclusion: After an elective caesarean section, more mothers were satisfied after receiving general anesthesia as compared to spinal anesthesia. However, both types of anaesthesia were found to be equally safe for babies born in terms of APGAR scores at 5 minutes.

Keywords: APGAR score, Cesarean section, General anesthesia, Patient satisfaction, Spinal anesthesia, Visual analogue scale.

\footnotetext{
This is an Open Access article distributed under the terms of the Creative Commons Attribution License (https://creativecommons.org/licenses/by-nc/4.0/), which permits unrestricted use, distribution, and reproduction in any medium, provided the original work is properly cited.
}

\section{INTRODUCTION}

For cesarean section (CS) choices of anesthesia can be general anesthesia (GA) or regional anesthesia of the operation site, considering the safety of mother and baby, as well as the clinical situation at hand. In 1898 Bier introduced spinal anesthesia (SA); as an alternative to $\mathrm{GA}^{1}$. Advantages of SP are early mobilization of patient, better post-surgery pain control and shorter hospital stay. However, SP has some disadvantages like hypotension and disturbance of bladder function. In contrast, GA in CS has advantages like less patient anxiety, less time for surgical readiness, better control of hemodynamic and patient preference. Disadvantages of $\mathrm{GA}^{2}$, are chances of regurgitation, more blood loss, delayed recovery and less mother baby bondage.

There is a dramatic rise in the rate of cesarean deliveries all over the world. The role of anesthetists is to choose the method which is comfortable for the mother but is least depressant to the newborn. APGAR score is used for rapid evaluation of neonatal well-

Correspondence: Dr Syed Khurram Naseer, Anaesthesia Department, Combined Military Hospital, Peshawar Pakistan

Received: 18 Sep 2019; revised received: 12 Jan 2020; accepted: 27 Jan 2020 being shortly after birth. Imtiaz et al, in their comparative study reported that after SP, $66.66 \%$ neonates had good APGAR scores at $1 \mathrm{~min}$ as compared to $16.66 \%$ in $\mathrm{GA}^{3}$. The second most important consideration after neonatal wellbeing is patient satisfaction. Many studies have investigated patient's satisfaction with SP care in $\mathrm{CS}^{4,6}$. Siddiqi et al. found patient's overall level of satisfaction with SP to be $81.40 \%{ }^{5}$. However none of these studies investigated patient satisfaction with GA. One of the reasons for this may be that currently no validated instruments are available which can assess patient satisfaction psychometrically during GA Oyle et al, in their study devised a simple method to measure satisfaction levels with GA care and found that among the patients receiving GA, 95.8\% were extremely or moderately satisfied, $3.1 \%$ were neutral, and $1.1 \%$ moderately or extremely dissatisfied ${ }^{8}$. However this study was conducted on patients undergoing maxillofacial procedures, so the results may differ in patients undergoing CS. We planned to study patient satisfaction levels with a simple visual analogue scale tool ${ }^{7}$.

In this study we compared the patient satisfaction after CS by two different modes of anesthesia. Moreover, we compared neonatal APGAR scores at 5 
minutes after delivery and previous work mostly gives evidence of APGAR scores at 1 or 3 minutes after delivery. The effect of GA on neonate reduces every minute after delivery. This information will give valuable information regarding decision making in anesthesia.

\section{METHODOLOGY}

It was a comparative cross sectional study conducted in the departments of Anesthesia and Gynecology and Obstetrics, Combined Military Hospital Peshawar, from March to August 2019. Ethics approval was obtained from hospital ethics committee (08). Sample size was calculated using patient's pain values (SA 16.5 vs GA 22.8) from Capdevila et al ${ }^{0}$, and using openepi sample size calculator; sample size was found to be 60 in each group A total of 120 women with a singleton pregnancy of 36-40 weeks (confirmed by ultrasound), and requiring a non-emergency elective CS were enrolled through non-probability consecutive sampling in study. Pregnant women were within the age range of 20-40 years. The patients were randomly allocated into two equal groups of 60 women each through random number table. Group A received SA and group B GA. All pregnant women having emergency CS or having pregnancy related problems Pregnancy Induced Hypertension (PIH), diabetes mellitus, intra uterine growth retardation (IUGR) and Placenta previa were excluded. Women having spinal problems or on drugs acting on central nervous system (antidepressants etc.) were excluded. Moreover, neonates with congenital anomalies or prolonged incision to delivery time (>15 minutes) were excluded. Women having intra-operative complication (hypotension or excessive bleeding) were also excluded.

APGAR score was assessed at 5 minutes after delivery, and score of $\geq 7$ was taken as satisfactory. Patient satisfaction level regarding anesthesia was recorded on a visual analogue scale of 0 (extremely unsatisfied) to 10 (completely satisfied), and score of $\geq 7$ was taken as satisfactory. Before conducting the study a formal approval was obtained from Hospital Ethics Committee. Patients were booked and admitted for elective lower segment cesarean section (LSCS) through our Hospital's Obstetric Outpatient Department (OPD). Selected patients were females with a singleton pregnancy of 36-40 weeks, diagnosed clinically and on ultrasound. After an informed (risks of both procedures were explained) written consent 120 patients, found eligible after applying the inclusion and exclusion criteria, were recruited through a consecutive non-probability sampling. Personal profile including name, age, gravida, parity, hospital admission number, address and phone number and date of admission were noted. History regarding number of previous CS was recorded. Pre-anesthesia assessment of all the patients was done and only American Society of Anesthesiologists (ASA) class 1 and 2 were included. All the patients were randomly allocated into two equal groups of 60 each by using random number tables. Group A was allocated to receive SP and group B was given GA. In "group-A" SP was given in space between lumbar 3 and lumbar 4 vertebrae using spinal needle of size 25 and injection Bupivacine $0.5 \% 12 \mathrm{mg}$ after pre loading the patient with $10 \mathrm{ml} / \mathrm{kg}$ crystalloid solution, under aseptic conditions. Supplemental oxygen at the rate of 4 liter/min was administered throughout the procedure via Hudson mask. In group-B GA was given using injection Propofol $2 \mathrm{mg} / \mathrm{kg}$, Injection Succinylcholine $1 \mathrm{mg} / \mathrm{kg}$ rapid sequence induction and intubation with Endo tracheal tube size 7-7.5, maintained with $50 \%$ oxygen $50 \%$ air and Isoflurane $1 \%$ and the patient was reversed with Neostigamine $0.04 \mathrm{mg} / \mathrm{kg}$ and Injection Glycopyrolate $0.01 \mathrm{mg} / \mathrm{kg}$. After the delivery of baby injection Nalbuphine 0.2 $\mathrm{mg} / \mathrm{kg}$ was given to the mother for analgesia. In both the groups monitoring of pulse, blood pressure, oxygen saturation, Electro-cardiogram and urinary output was done. In all the patients, APGAR score was assessed by the researcher/neonatologist at 5 minutes after delivery by the standard method. APGAR score of 7 or more was taken as 'satisfactory', and $<7$ was taken as unsatisfactory.

Patient satisfaction level regarding the anesthesia method was recorded at the time of discharge from the hospital. Patient satisfaction regarding anesthesia method was noted on a visual analogue scale (VAS) from $0-10$ and VAS score $\geq 7$ was taken as satisfaction positive (or satisfactory) whereas score of 0-6 was taken as satisfaction negative (or un-satisfactory $)^{7}$. All the data was recorded by filling in or checking the boxes on a specifically designed proforma. Data analyst was blinded about the study groups.

All the collected data was entered in Statistical Package of Social Sciences (SPSS) version 20. Age was presented as Mean \pm SD. Categorical variables APGAR scores, sex of the baby and patient satisfaction were presented as frequency and percentage. Chi-square test was used to compare patient satisfaction between anesthesia, sex of baby and APGAR score groups. The $p$ value of $\leq 0.05$ was taken as significant for chi square analysis. 


\section{RESULTS}

Collectively in both the groups, the age of patients ranged between $20-40$ years with mean $26.57 \pm 5.86$ years. Out of the 120 total new born babies 64 (53.33\%) were males and $56(46.66 \%)$ were females.

In SP group $54(90 \%)$ newborn babies had satisfactory scores and $6(10 \%)$ babies had unsatisfactory scores. While in GA group $50(83.33 \%)$ babies had satisfactory scores and $10(16.66 \%)$ had unsatisfactory scores. However, this difference was not statistically significant $(p=0.283)$.

Mothers in both groups were satisfied with anaesthesia, however, women in GA group were more satisfied (GA $95 \%$ vs SA $78.3 \%, p=0.007$ ) as compared to SP group (table-II). Patient satisfaction was also evaluated in terms of sex of baby, as it may be a potential confounder; influencing maternal satisfaction. Most of the mothers were satisfied regarding the sex of baby (male $82 \%$ vs female $91.1 \%$ ) and the comparison was not statistically significant $(p=0.184)$ (table-III).

Table-I: Comparison of APGAR scores in spinal and general anesthesia groups $(n=120)$.

\begin{tabular}{l|c|c|c|c}
\hline \multicolumn{2}{c|}{} & \multicolumn{2}{|c|}{$\begin{array}{c}\text { APGAR Score } \\
\text { Satisfactory }\end{array}$} & \multirow{2}{*}{$\begin{array}{c}\boldsymbol{p} \text { - } \\
\text { value }\end{array}$} \\
\cline { 3 - 4 } \multicolumn{2}{c|}{} & Yes & No & \\
\hline $\begin{array}{l}\text { Anesthesia } \\
\text { Group }\end{array}$ & Spinal & $54(90)$ & $6(10)$ & \multirow{2}{*}{0.283} \\
\cline { 2 - 4 } & General & $50(83.3)$ & $10(16.7)$ & \\
\hline
\end{tabular}

Table-II: Patient satisfaction in spinal and general anesthesia $(n=120)$.

\begin{tabular}{|c|c|c|c|c|}
\hline & \multicolumn{2}{|c|}{ Patient Satisfaction } & \multirow{2}{*}{$\begin{array}{c}p \text { - } \\
\text { value }\end{array}$} \\
\hline & & Yes & No & \\
\hline \multirow{2}{*}{$\begin{array}{l}\text { Anesthesia } \\
\text { Group }\end{array}$} & Spinal n (\%) & $47(78.3)$ & $13(21.7)$ & \multirow{2}{*}{0.007} \\
\hline & General n (\%) & $57(95)$ & $3(5)$ & \\
\hline
\end{tabular}

Table-III: Association of patient satisfaction according to gender of the baby $(n=120)$.

\begin{tabular}{|c|c|c|c|c|}
\hline & \multicolumn{2}{|c|}{ Patient Satisfaction } & \multirow{2}{*}{$\begin{array}{c}p \text { - } \\
\text { value }\end{array}$} \\
\hline & & Yes & No & \\
\hline \multirow{2}{*}{$\begin{array}{l}\text { Gender of } \\
\text { Baby }\end{array}$} & Male n (\%) & $53(82.8)$ & $11(17.2)$ & \multirow{2}{*}{0.184} \\
\hline & Female $\mathrm{n}(\%)$ & 51 (91.1) & $5(0.9)$ & \\
\hline
\end{tabular}

\section{DISCUSSION}

Satisfaction of mother as well as maternal and neonatal safety are both prerequisite for choice of anesthesia for CS, and are the two most important factors to be considered while choosing between spinal or GA for an elective Caesarean section.

We used APGAR score to measure fetal wellbeing and a visual analogue scale to assess patient satisfaction. SA was found to be slightly but not significantly better than GA in terms of neonatal APGAR scores. Moreover, SA was not found superior to GA in terms of patient satisfaction, and patients undergoing GA were more satisfied.

A lot of studies have been conducted to compare SA with GA for CS. A meat-analysis by Afolabi et $a l^{9}$, evaluated the use of SA vs GA for CS in almost 1800 women in 29 studies $^{9}$. In terms of patient satisfaction, risk ratio (RR) of SA vs GA was 0.80 , showing more patient satisfaction with $\mathrm{GA}^{9}$. Moreover, women who went under GA wanted the same procedure for future pregnancies, showing increased satisfaction. Same was observed in our study that patient satisfaction was more with $\mathrm{GA}^{9}$. No significant difference was seen in terms of low neonatal APGAR scores at five minutes and the need for neonatal resuscitation with oxygen9. Same results regarding no difference in APGAR scores were observed in our study. However, their study was carried out for emergency cesareans as compared to elective procedures in our study. In this regard, further research to evaluate maternal outcomes in relation to satisfaction with technique, would be useful.

Our results regarding APGAR scores were in contrast to Mancuso et al. Study which stated different median APGAR scores in both SA and GA groups (Kruskal-Wallis test $p=0.001)^{10}$.

Our results differed from Afolabi et al, as according to them APGAR scores even at 5 minutes were found to be significantly lower for the GA group than the group SA and need for respiratory assistance was greater for the GA group ${ }^{9}$.

Abdallah et al, reported that the APGAR scores taken at 1 and 5 min were significantly higher in newborns of parturient who received SP than in neonates who were delivered under GA (SA $7.5 \pm 1.7$ vs GA $6.3 \pm 1.12, p \leq 0.05)^{11}$. Mekonan et al, also observed that lower APGAR scores at 1 minute were significantly more prevalent among child who underwent LSCS with GA, compared to those who underwent LSCS with SA $\left(\mathrm{OR}=2.54,95 \% \mathrm{CI}=(1.26,25.4)^{12}\right.$. Postoperative nausea and vomiting were found more prevalent in the SA group. In addition mothers with SP had more demands for analgesics postoperatively ${ }^{12}$.

Many studies have reported low APGAR scores at 1 minute with GA as compared to SA. Ozgen et al. Observed that the APGAR scores at the $1^{\text {st }}$ min were significantly higher in combined spinal-epidural anesthesia as compared to GA (SA $9.2 \pm 0.6$ vs GA $8.4 \pm$ $1.2)^{13}$. Tudjegbe et al, observed that GA was significantly associated with low APGAR scores at 1 minute $(p=0.0056, \mathrm{RR}=1.6,95 \% \mathrm{CI}=1.2-2.2)^{14}$. However, our results should not be compared with these studies, as 
our study did not compare APGAR scores at 1 minute; it compared APGAR score at 5 minutes instead. APGAR score at 5 minutes is an important variable and several obstetric risk factors are associated with low 5-minute APGAR score in term infants. Mortality and the risk of severe neurologic morbidity are increased in infants with low APGAR score at $5 \mathrm{~min}$.

Sayg et al, in their study find that post-operative pain in terms of verbal rating scale (VRS) was more in GA versus SA ( $6.7 \pm 1.9$ vs $6.3 \pm 2.3, p=0.304)$, so SA is superior to GA in terms of postoperative patients comfort ${ }^{15}$. Some of the reasons for preference of GA over SA are postoperative pain at the injection site after regional anesthesia post dural puncture headache, and back ache ${ }^{16}$. Basak Altiparmak et al, found that the patients undergoing CS receiving both of the anesthesia techniques were more satisfied by SP, while there was no difference found between preoperative anxiety levels ${ }^{17}$. Elkady et al. stated that GA is thought to be the quickest anesthesia method in an emergency as it avoids the possibility of a failed regional block, however, it can be associated with higher possibility of blood loss and low APGAR score. Thus, using SP for elective CS is recommended provided that adequate vascular volume is achieved and leaving GA for emergency caesarean sections or where SP is contra indicated (e.g. coagulopathy, severe thrombocytopenia, anti-coagulation or severe degree of malformation of spine $)^{18}$.

Mothers were more satisfied with GA as compared to SA according to our results. This is in accordance to a meta-analysis that stated that more women in the GA group would prefer to use the same technique again for subsequent pregnancies ${ }^{9}$. However; satisfaction with technique was not well studied, probably because no psychometrically validated instrument that could measure patient satisfaction during GA was available ${ }^{19}$. Okwuchukwu et al, stated that SA was associated with reduced risk of blood loss and better APGAR score in the $1^{\text {st }} \mathrm{min}$. There was no difference in APGAR score at $5 \mathrm{~min}$ and maternal and neonatal mortality ${ }^{20}$. As long as it is not contraindicated, SP during elective C-section was safer for both neonates; higher APGAR scores, and mother; less bleeding, less postoperative pain and can be the ideal anesthesia and method of choice during elective C-section ${ }^{21}$. Lertakyamanee et al, were probably the first one to use a visual analogue score for maternal satisfaction and observed that there was no difference in the level of satisfaction when comparing GA with $\mathrm{SA}^{22}$.
Some of the limitations are that we have used visual analogue scale for this study which is not the ideal tool to study patient satisfaction levels. It is a popular method to study pain and has not been used to measure satisfaction very commonly. Future studies should device a more objective and psychometrically validated scale.

\section{CONCLUSION}

After an elective CS, mother's satisfaction was more with GA in comparison to SA; however, both types of anaesthesia were equally safe for neonates in terms of neonatal APGAR scores at 5 minute. Hence GA is the preferred anesthesia for elective CS considering patient satisfaction.

\section{CONFLICT OF INTEREST}

This study has no conflict of interest to be declared by any author.

\section{REFERENCES}

1. Brown TC. History of pediatric regional anesthesia. Paediatr Anaesth 2012; 3(1): 3-9.

2. Sultan S, Rana S, Hafeez A, Tariq U, Firdous R. Comparison of general and spinal anesthesia in patients undergoing open abdominal hernia repair in terms of post-operative pain. Ann Punjab Med Coll 2018; 12(1): 70-73.

3. Imtiaz A, Mustafa S, Masroorudin M, Haq NU, Ali SH, Imtiaz K. Effect of spinal and general anesthesia over APGAR score in neonates born after elective Cesarean section. J Liaquat Uni Med Health Sci 2010; 9(3): 151-54.

4. Tan DJA, Sultana R, Han NLR, Sia ATH, Sng BL. Investigating determinants for patient satisfaction in women receiving epidural analgesia for labour pain: a retrospective cohort study. BMC Anesthesiol 2018; 18(1): 50-55.

5. Siddiqi R. Maternal satisfaction after spinal anesthesia for cesarean deliveries. J Coll Physicians Surg Pak 2009; 19(2): 77-80.

6. Capdevila X, Aveline C, Delaunay L, Bouaziz H, Zetlaoui P, Choquet $\mathrm{O}$, et al. Factors determining the choice of spinal versus general anesthesia in patients undergoing ambulatory surgery: results of a multicenter observational study. Adv Ther 2020; 37(1): 527-40.

7. Morgan PJ, Halpern S, Lo J. The development of a maternal satisfaction scale for caesarean section. Int J Obstet Anesth 1999; 8(3): 165-70.

8. Droog W, Hoeks SE, van Aggelen GP, Lin DY, Coert JH, Stolker RJ, et al. Regional anaesthesia is associated with less patient satisfaction compared to general anaesthesia following distal upper extremity surgery: a prospective double centred observational study. BMC Anesthesiol 2019; 19(1): 115-18.

9. Afolabi BB, Lesi FE. Regional versus general anaesthesia for caesarean section. Cochrane database Syst Rev 2012; 10(2): CD004350.

10. Mancuso A, De Vivo A, Giacobbe A, Priola V, Maggio-Savasta L, Guzzo M, et al. General versus spinal anaesthesia for elective caesarean sections: effects on neonatal short-term outcome. A prospective randomised study. J Matern Fetal Neonatal Med 2010; 23(10): 1114-18.

11. Abdallah MW, Elzayyat NS, Abdelhaq MM, Gado AM. A comparative study of general anesthesia versus combined spinal- 
epidural anesthesia on the fetus in cesarean section. Egypt J Anaesth 2014; 30(2): 155-60.

12. Mekonen S, Eshete A, Desta K, Molla Y. Maternal and neonatal outcomes in mothers who undergo caesarean section under general and spinal anesthesia in Gandhi memorial hospital, Addis Ababa. Adv Tech Biol Med 2015; 3(1): 5-10.

13. Ozgen ZS, Toraman F, Erkek E, Sungur T, Guclu P, Durmaz S, et al. Cesarean under general or epidural anesthesia: does it differ in terms of regional cerebral oxygenation?. Acta Anaesthesiol Taiwan 2014; 52(4): 159-62.

14. Tudjegbe SO, Imarengiaye CO, Sadoh WE. Determinants of paediatrician's presence at caesarian section. West Afr J Med 2012; 31(1): 24-27.

15. Sayg1 AI, Özdamar O, Gün I, Emirkadı H, Müngen E, Akpak YK. Comparison of maternal and fetal outcomes among patients undergoing cesarean section under general and spinal anesthesia: a randomized clinical trial. Sao Paulo Med J 2015; 133(3); 227-34.

16. Sadeghi M, Bayat R, Azimaraghi O, Saliminia A. Maternal satisfaction of spinal anesthesia for elective cesarean section in an academic hospital. Ann Anesth Crit Care 2017; 2(2): e62239.

17. Başak K, Sezen BK. Assessment of satisfaction and anxiety levels of the patients who had cesarean section with general and spinal anesthesia. Med Sci 2017; 6(2): 229-32.

18. Ateeyah H, Elkady M, Mostafa M, Mohamed M. Maternal and fetal outcomes in women undergoing caesarean section under general and spinal anesthesia. Egypt J Hosp Med 2018; 72(7): 4856-65.

19. Hawkins RJ, Swanson B, Kremer MJ. An integrative review of factors related to patient satisfaction with general anesthesia care. AORN J 2012; 96(4): 368-76.

20. Obi VO, Umeora OU. Anesthesia for emergency cesarean section: A comparison of spinal versus general anesthesia on maternal and neonatal outcomes. Afr J Med Health Sci 2018; 17(1): 3134.

21. Madkour NM, Ibrahim SA, Ezz GF. General versus spinal anesthesia during elective cesarean section in term low-risk pregnancy as regards maternal and neonatal outcomes: a prospective, controlled clinical trial. Res Opin Anesth Intens Care 2019; 6(1): 119-24.

22. Lertakyamanee J, Chinachoti $\mathrm{T}$, Tritrakarn $\mathrm{T}$, Muangkasem J, Somboonnanonda A, Kolatat T. Comparison of general and regional anesthesia for cesarean section: success rate, blood loss and satisfaction from a randomized trial. J Med Assoc Thai 1999; 82(7): 672-80. 